\title{
Trial order and retention interval in human predictive judgment
}

\author{
STEVEN C. STOUT \\ Valdosta State University, Valdosta, Georgia \\ and \\ JEFFREY C. AMUNDSON and RALPH R. MILLER \\ State University of New York, Binghamton, New York
}

\begin{abstract}
The influences of order of trial type and retention interval on human predictive judgments were assessed for a cue that was reinforced on half of its training presentations. Subjects observed 10 cue-outcome presentations (i.e., reinforced trials) and 10 cue-alone presentations (i.e., nonreinforced trials) in one of three different orders: all nonreinforced trials followed by all reinforced trials (latent inhibition), reinforced and nonreinforced trials interspersed (partial reinforcement), or all reinforced trials followed by all nonreinforced trials (extinction). Ratings were based mainly on the most recent event type (i.e., a recency effect) when the test occurred immediately after training but were based mainly on initial event types (i.e., a primacy effect) when the test occurred after a 48-h delay. The subjects tested both immediately and with a long retention interval did not exhibit this shift to primacy (i.e., the recency effect persisted). These results demonstrate noncatastrophic forgetting and the flexible use of trial order information in predictive judgments.
\end{abstract}

Of all the cognitive tasks that animals, including humans, perform, surely few are more important than the ability to predict future events on the basis of past events. Throughout much of the 20th century, the systematic study of this type of simple inference was concentrated among investigators of Pavlovian conditioning (Pavlov, 1927). In Pavlovian conditioning, subjects are exposed to an initially neutral conditioned stimulus (CS; e.g., a light), followed by an unconditioned stimulus (US; e.g., an electric shock). With repeated pairings of the two (light and shock), subjects come to display conditioned responses to the light that are anticipatory in nature (e.g., freezing in response to the light). Phrased more cognitively, with repeated CS-US pairings, subjects increasingly behave as if they expect the US to recur when the CS is presented on a test trial. Investigators in this area have identified a large number of basic variables that control how rapidly and to what level this anticipatory behavior develops (for summaries of the controlling variables of Pavlovian conditioning, see Hearst, 1988; Miller \& Escobar, 2002).

Reviving an older line of work by Jenkins and Ward (1965), since the 1980s, many cognitive psychologists

We thank Oskar Pineño, Daniel Wheeler, Gonzalo Urcelay, and Kouji Urushihara for their comments on a draft of the manuscript. We also thank Danielle Gutter, Jamie Francis, Leanne Scalli, and Gonzalo Urcelay for help in running the experiments. We are indebted to Deanne Westerman for theoretical discussions regarding this experiment. Inquiries concerning this research should be addressed to R. R. Miller, Department of Psychology, SUNY, Binghamton, NY 13902-6000 (e-mail: rmiller@binghamton.edu). have studied analogous tasks involving human subjects in which the "conditioned response" is a verbally expressed judgment of the likelihood that an outcome will again follow a cue with which it has been accompanied during past trials. For example, subjects might diagnose the likelihood that a patient will develop an allergy after having consumed some food that was paired or not paired with allergies in the past (Allan, 1993). An interesting finding of studies of this type has been the large extent to which human predictive judgments are affected by the same variables that affect nonhuman animals' conditioned responses, particularly in competition between multiple predictor cues for control over behavior (for reviews, see Allan, 1993; Shanks, Holyoak, \& Medin, 1996). Given their operational similarity, the conclusion that these preparations obey similar principles is not surprising (Allan, 1993; Dickinson, Shanks, \& Evenden, 1984; Gluck \& Bower, 1988; Shanks \& Dickinson, 1987). In fact, the similarities are so many in number that several investigators within the field routinely use associative and nonassociative models originally developed to explain Pavlovian conditioning to explain human predictive and causal judgments. However, largely because the study of predictive judgment is younger than the study of Pavlovian conditioning, the potential influence of many basic variables known to influence Pavlovian conditioning and, thus, the soundness of correspondence between these two types of inference remains to be fully explored.

One variable that has received recent attention in both areas is trial order. In Pavlovian conditioning, the simplest trial order tasks are those in which pairings of the CS and 
the US and presentations of the CS alone are segregated into separate phases. Experimental extinction (EXT) typically involves a phase of continuously reinforced trials (i.e., CS $\rightarrow$ US trials), followed by a phase of continuously nonreinforced trials (i.e., CS-no-US trials). The result is that conditioned responding increases during the reinforced phase and declines during the EXT (i.e., nonreinforced) phase (Pavlov, 1927). In the latent inhibition (LI) procedure, a phase of nonreinforced trials occurs prior to a phase of reinforced trials. The result here is that little to no conditioned responding occurs in the first phase and that responding increases slower during the second phase than in a control group that is not preexposed to the CS (Lubow \& Moore, 1959). The effect of trial order in such two-phase conditioning procedures can be assessed by comparing responding after LI and EXT treatments in independent groups. Recently, Lubow and De la Casa (2002) and our own lab (Wheeler, Stout, \& Miller, 2004), using nonhuman subjects, have found that if Pavlovian testing soon follows training, subjects receiving LI treatment display much higher conditioned responding than do those receiving EXT treatment. Borrowing language from studies of human memory, a strong recency bias is observed in conditioned responding.

A few studies have been performed to examine trial order effects in predictive judgment tasks. Of central concern in these studies has been the class of model best suited to account for predictive judgment data. Associative models, such as that of Rescorla and Wagner (1972) and its derivatives, such as that of Van Hamme and Wasserman (1994), posit that an association between an internal representation of the cue and the outcome is modulated on a trial-by-trial basis by experimental treatments of the two associates. By contrast, statistical models, many of which follow Rescorla's (1968) proposal, such as that in Cheng and Novick (1990), postulate that predictive judgments represent a transform of the cells of a contingency matrix (for reviews, see Allan, 1993; Young, 1995). In simple situations involving a cue and an outcome that can each be present or absent on a given trial, a popular model states that judgments will reflect a comparison $(\Delta p)$ of the probability of the outcome in the presence of the cue (C) with the probability of the outcome $(\mathrm{O})$ in its absence $[\Delta p=$ $p(\mathrm{O} \mid \mathrm{C})-p(\mathrm{O} \mid$ no $\mathrm{C})$; Allan, 1980]. One major distinction between these two classes is that associative models clearly predict recency effects, whereas statistical models (as formulated by $\Delta p$ ) do not predict order effects at all without additional assumptions. Lopez, Shanks, Almaraz, and Fernandez (1998) found that when people were exposed to cueoutcome contingencies such that the overall $\Delta p$ was zero, they were biased more by recent than by early trial types. Lopez et al. took this finding as evidence favoring an associative view of judgment. In contrast, Dennis and Ahn (2001) and Yates and Curley (1986) found the opposite, a primacy effect. Primacy is not explicitly predicted by either class of models but is easily accommodated by a number of traditional and contemporary models of human memory that have not, to date, been integrated into either the predictive judgment or the Pavlovian conditioning literature (e.g., Hintzman's, 1984, MINERVA 2). Toward resolving these discrepant findings, Collins and Shanks (2002) and Matute, Vegas, and De Marez (2002) found that recency effects predominated in situations in which subjects made judgments on a per trial basis, whereas Collins and Shanks observed small primacy effects and Matute et al. observed unbiased responding when subjects made a single judgment at the end of treatment. Both teams of investigators concluded that models of predictive judgment will have to be modified to take into account the recency bias promoted by making judgments on a trial-to-trial basis.

The present investigation concerns an additional variable known to strongly interact with primacy and recency effects in both the animal conditioning and the basic human memory literature: the retention interval. With respect to traditional studies of human memory, a nearly ubiquitous principle is that recency effects decline as the retention interval increases. A second pattern that has garnered attention has been called the recency-to-primacy shift (see, e.g., Knoedler, Hellwig, \& Neath, 1999; Neath, 1993; Neath \& Knoedler, 1994; Postman, Stark, \& Fraser, 1968; called spontaneous recovery in the old verbal learning and Pavlovian literatures). In this case, fading recency is accompanied by enhancement of retrieval of earlier items (i.e., a primacy effect). A traditional view is that enhancement of initial memory over time is hard to observe unless it is measured as retrieval relative to all items, in which case it might represent differential rates of forgetting (e.g., Crowder, 1976). But Neath and his colleagues have supplied a number of demonstrations of absolute primacy enhancement with the passage of time, rekindling a debate over its nature (Kerr, Avons, \& Ward, 1999).

A similar effect has been observed in nonhumans in Pavlovian preparations. Following EXT treatment, as the retention interval is lengthened, the magnitude of the conditioned response to the CS increases (called spontaneous recovery; see, e.g., Burdick \& James, 1970; Ellson, 1939; Pavlov, 1927). Moreover, following LI treatment, as the retention interval is lengthened, the magnitude of conditioned response to the CS decreases (called super LI; see, e.g., De la Casa \& Lubow, 2000, 2002). ${ }^{1}$ Because LI and EXT treatments differ only in trial order, direct comparisons of the two allow for an assessment of primacy, recency, and, if a retention interval is manipulated, a recency-to-primacy shift. As was previously stated, Lubow and De la Casa (2002) and our own lab (Wheeler et al., 2004) found a strong recency bias if testing immediately followed training. However, if a long retention interval was imposed between the second phase of treatment and testing, subjects receiving LI treatment displayed much lower conditioned responding than did those receiving EXT treatment. That is, the results were inverted, relative to the short retention interval, in that a primacy effect was observed. Importantly, in both studies, the primacy effect was absolute, rather than merely relative.

In the present study, we investigated potential changes in trial order effects as a function of retention interval in a predictive judgment task. Our question was the following: When a long retention interval follows sequentially 
experienced contradictory cue-outcome relationships, do people treat the situation as though the last experienced relationship continues to hold (recency), as though either relationship could occur (i.e., neutrality), or as if the firstexperienced relationship holds again (primacy)? Should a change in subjective ratings be observed - either loss of recency or a shift from recency to primacy - several theoretical implications would arise for contemporary formal models of predictive judgment, because current models of predictive judgment do not anticipate any effect of retention interval. For example, such findings would challenge Lopez et al.'s (1998) conclusion that recency effects unambiguously support associative models.

Only Vila and Rosas (2001) have demonstrated a change in estimates with time in a predictive judgment task. They observed spontaneous recovery to occur following a 48-h retention interval in a task in which subjects were first told of fictitious patients who received a medicine, followed by stomach upset for several trials, and then were told of the medicine's being taken without being followed by stomach upset for several trials. When tested immediately after this experiential sequence, ratings of the medicine as a potential cause of stomach upset were low. Consistent with the occurrence of spontaneous recovery, causal ratings were higher in subjects tested after a 48-h retention interval. As Lubow and De la Casa (2002) noted, this design, as with typical LI designs, fails to discriminate the extent to which judgment is impacted by trial order, because the control group of traditional EXT (and LI designs) is a continuously reinforced group, thereby confounding reinforcement probability and trial order, relative to the target group. Thus, such studies cannot speak to whether trial order interacts with retention interval.

The present report assessed the extent to which such changes with time represent a reversion to control by primacy, as opposed to a nonspecific increase or decrease per se. This was chiefly accomplished by our including both EXT and LI groups, the ratings of which would be expected to increase and decrease, respectively, were a recency-to-primacy shift to occur. Furthermore, a partial reinforcement condition was included as an additional manipulation of trial order. In partial reinforcement training, fixed proportions of reinforced and nonreinforced trials were maintained across trials. Thus, following partial reinforcement, even if there was a recency effect or a recency-to-primacy shift, ratings should be unaffected by retention interval. The performance of this group was intended to facilitate differentiation between a shift from recency to primacy and a simple integration of the two types of memories (i.e., of reinforced trials and nonreinforced trials). To our knowledge, no single experiment has ever directly compared responding elicited by all three types of trials. In order to minimize potential confounds, the subjects observed trial types without receiving any specific instructions concerning what they would observe; there was no obvious demarcation between individual trials or phases of treatment, and the cues and the outcome bore no preexisting relationship to each other.

\section{METHOD}

\section{Design}

The subjects were given 10 reinforced and 10 nonreinforced trials on a computer monitor (see Table 1). The cue was either a red inverted $\mathrm{U}$ or a blue square, and the outcome was a picture of a human infant. Six groups made up a factorial cross of trial order and retention interval. For two groups of subjects, all 10 of the nonreinforced trials were followed by all 10 of the reinforced trials (the LI condition), for two groups the two trial types were randomly interspersed (the partial reinforcement [PR] condition), and for two groups all of the reinforced trials were followed by all of the nonreinforced trials (the EXT condition). Immediately after this 20-trial sequence, half of the subjects in each condition were asked to rate the likelihood that the picture of the baby would immediately follow the target shape,

Table 1

Design Summary

\begin{tabular}{|c|c|c|c|c|}
\hline Group & Phase 1 & Phase 2 & $\begin{array}{c}\text { Test } \\
\text { Immediately }\end{array}$ & $\begin{array}{l}\text { Test } \\
48 \mathrm{~h}\end{array}$ \\
\hline LI-Short & $\mathrm{X}-$ no-O & $\mathrm{X} \rightarrow \mathrm{O}$ & yes & ye \\
\hline PR-Short & $\mathrm{X} \rightarrow \mathrm{O} / \mathrm{X}-$ no-O & $\mathrm{X} \rightarrow \mathrm{O} / \mathrm{X}-$ no- $\mathrm{O}$ & yes & $\mathrm{y}$ \\
\hline EXT-Short & $x \rightarrow O$ & $\mathrm{X}$-no-O & yes & y \\
\hline LI-Long & $\mathrm{X}-$ no-O & $x \rightarrow O$ & no & y \\
\hline PR-Long & $\mathrm{X} \rightarrow \mathrm{O} / \mathrm{X}-$ no-O & $\mathrm{X} \rightarrow \mathrm{O} / \mathrm{X}-$ no-O & no & y \\
\hline \multirow{2}{*}{\multicolumn{5}{|c|}{ CR-Short }} \\
\hline & & & & \\
\hline Subgroup A & $X \rightarrow O$ & A-no-O & yes & y \\
\hline Subgroup B & A-no-O & $x \rightarrow 0$ & yes & y \\
\hline \multicolumn{5}{|l|}{ CR-Long } \\
\hline Subgroup A & $X \rightarrow O$ & A-no-O & no & \\
\hline Subgroup B & A-no-O & $X \rightarrow O$ & no & y \\
\hline \multicolumn{5}{|l|}{ None } \\
\hline Subgroup A & $\mathrm{A} \rightarrow \mathrm{O}$ & $\mathrm{X}-$ no-O & no & $y$ \\
\hline Subgroup B & $\mathrm{X}$-no-O & $\mathrm{A} \rightarrow \mathrm{O}$ & no & yes \\
\hline
\end{tabular}

Note-LI, latent inhibition; PR, partial reinforcement; EXT, extinction; CR, continuous reinforcement (i.e., reinforcement training only); None, nonreinforcement treatment only; X and A, geometric shapes; O, picture of human baby presented for $1 \mathrm{sec}$; Short, 7-sec retention interval; Long, 48-h retention interval; average intertrial interval in treatment $=7 \mathrm{sec}$. Subgroups A and $\mathrm{B}$ were collapsed in the final analysis of the data. 
whereas the other half of the subjects were asked to leave the room and to return $48 \mathrm{~h}$ later. In addition to these six groups, subjects in three control groups saw the two different shapes, each one uniquely correlated with reinforcement or nonreinforcement. These groups provided controls for how probability of reinforcement affected responding to the test cue (X) in the six experimental groups. Two of these groups received the target shape continuously reinforced (the $\mathrm{CR}$ condition) in one phase and the nontarget shape continuously nonreinforced in the other phase. One of these two groups was tested immediately following training, and the other group was tested following a 48-h retention interval. The last group experienced the target stimulus consistently without reinforcement and the control stimulus with reinforcement (the None condition). This group was tested only following a 48-h retention interval.

\section{Subjects}

The subjects were 126 undergraduate students at the State University of New York at Binghamton, who participated in partial fulfillment of a course requirement. After reading and signing an informed consent form that noted the need to return in $48 \mathrm{~h}$ to receive full credit, they were assigned to one of nine main treatment groups, counterbalanced as best as possible for gender: LI-Short, PR-Short, EXT-Short, LI-Long, PR-Long, EXT-Long, CR-Short, CR-Long, or None. The number of subjects within each group ranged from 11 to 14 .

\begin{abstract}
Apparatus
The experiments were conducted on six IBM-compatible PCs. Inputs were made through a standard keyboard. All visual stimuli were displayed on 14-in. VGA monitor screens. SuperLab Pro 2.0 (Cedrus) was the software application used to present the stimuli and to record responses. A picture of a red inverted $\mathrm{U}$ or a blue square, each measuring $4 \times 4 \mathrm{~cm}$, was used as the cue (X or A, counterbalanced within groups). A humorous picture of a cross-eyed human baby measuring $4 \times 4 \mathrm{~cm}$ was used as the outcome. The stimuli were presented on a black background. The black background alone was displayed during intertrial intervals.
\end{abstract}

\section{Procedure}

At the beginning of the experiment, each subject was presented with the following set of instructions on the computer screen:

\section{Instructions}

This is an investigation of how people learn. It is not a test of your personal abilities or skills. Your name will not be linked with any of the data. You are about to witness several intermittent events on the computer monitor. These events will last for about five minutes. During this time, please do not look away from the monitor, as you might miss seeing an event. At any time you may be asked a question concerning what you have seen. The question will have a rating scale below it.

$$
<<\text { Press the SPACE BAR to continue }>>
$$

The subjects next saw a sequence of 20 trials presented on the screen. There were two types of trials. On nonreinforced trials, a shape was presented for $2 \mathrm{sec}$, followed by an intertrial interval. On reinforced trials, a shape was presented for $2 \mathrm{sec}$, followed immediately by the picture of the baby for $1 \mathrm{sec}$. The time between trial termination and trial onset was 3, 7, or $11 \mathrm{sec}$, varied randomly (mean intertrial interval $=7 \mathrm{sec}$ ). Six groups of subjects saw only the target shape, X. For these subjects, the order of the trial types was varied to create three conditions. In the LI condition, $10 \mathrm{X}-$ no-O trials were followed by $10 \mathrm{X} \rightarrow \mathrm{O}$ trials. In the PR condition, $10 \mathrm{X}-$ no-O and 10 $\mathrm{X} \rightarrow \mathrm{O}$ trials alternated randomly in one of two pseudorandom sequences. Each pseudorandom sequence was the mirror image of the other. Each of them was administered to half of the subjects in the PR condition. In the EXT condition, $10 \mathrm{X} \rightarrow \mathrm{O}$ trials were presented first, followed by $10 \mathrm{X}-$ no-O trials. The subjects in the other two conditions, CR and None, received 10 trials with one and 10 trials with the other of the two shape cues. Those in the CR condition received 10 consecutive $\mathrm{X} \rightarrow \mathrm{O}$ trials and 10 consecutive $\mathrm{A}-$ no-O trials, with half seeing the $X \rightarrow O$ trials first (Subgroup a) and half seeing the A-no-O trials first (Subgroup b). The subjects in the None condition received 10 consecutive $\mathrm{X}$-no-O trials and 10 consecutive $\mathrm{A} \rightarrow \mathrm{O}$ trials, again counterbalanced in order across two subgroups. Half of the subjects in the LI, PR, EXT, and CR conditions were tested following a short (7-sec) retention interval, and half following a long (48-h) retention interval (the first eight groups in Table 1). All the subjects in the None condition were tested with the long retention interval (the ninth group in Table 1).

The subjects in the short condition saw their sequence of treatment events followed immediately $(7 \mathrm{sec})$ by a screen with the target shape $(\mathrm{X})$ in the same screen position as before and, below it, the following question:

What is the probability that the baby will follow next?

Using a scale from $0 \%$ to $100 \%$, VERY CAREFULLY enter an estimate and then press the SPACE BAR to record your estimate. It is not necessary to enter the '\%' symbol.

Upon entering their estimate, they then saw a screen telling them that they could leave and asking them to return in 2 days at the same time.

The subjects in the long condition bypassed the rating screen and, instead, saw just the screen asking them to return in 2 days. All the subjects were asked to return in order to prevent differences in mortality from being confounded with the retention interval. That is, the subjects in the short condition who failed to return were scheduled to have their data dropped from the study. Forty-eight hours later, the subjects returned and initially saw the following screen:

$$
<<\text { Press the SPACE BAR to continue }>>
$$

Seven seconds after pressing the space bar, the target shape on the rating screen described above was presented. After their rating had been entered and the space bar had been pressed, a debriefing screen was presented.

\section{RESULTS}

The results of the experiment are presented in Figure 1. As can be seen in the LI, PR, and EXT conditions, trial order and retention interval interacted to influence the subjects' predictive ratings. The subjects tested immediately after training (white bars) gave predictive ratings that reflected the most recently experienced trial types. That is, for these subjects, responding was highest following the LI sequence, intermediate following the PR sequence, and lowest following the EXT sequence; that is, a recency effect was observed. Following the 48-h retention interval (black bars), this pattern of rating was reversed, and ratings were congruent with the first-experienced trial types. That is, a recency-to-primacy shift was observed between subjects after a long retention interval. The ratings in both CR groups were high and minimally affected by retention interval. The None control group demonstrated stimulus specificity of reinforcement with their low average ratings. Figure 2 depicts the ratings of the subjects in the short conditions on their first and second rating trials. As can be seen, these subjects evidenced little change in responding over the retention interval. A recency effect was observed regardless of the retention interval. Statistical analyses confirmed these impressions.

Of the 126 students participating in this study, 11 failed to enter data on at least one of the two sessions: 2 students from the LI-Short group, 1 from the PR-Short group, 1 from the LI-Long group, 1 from the PR-Long group, 2 from 


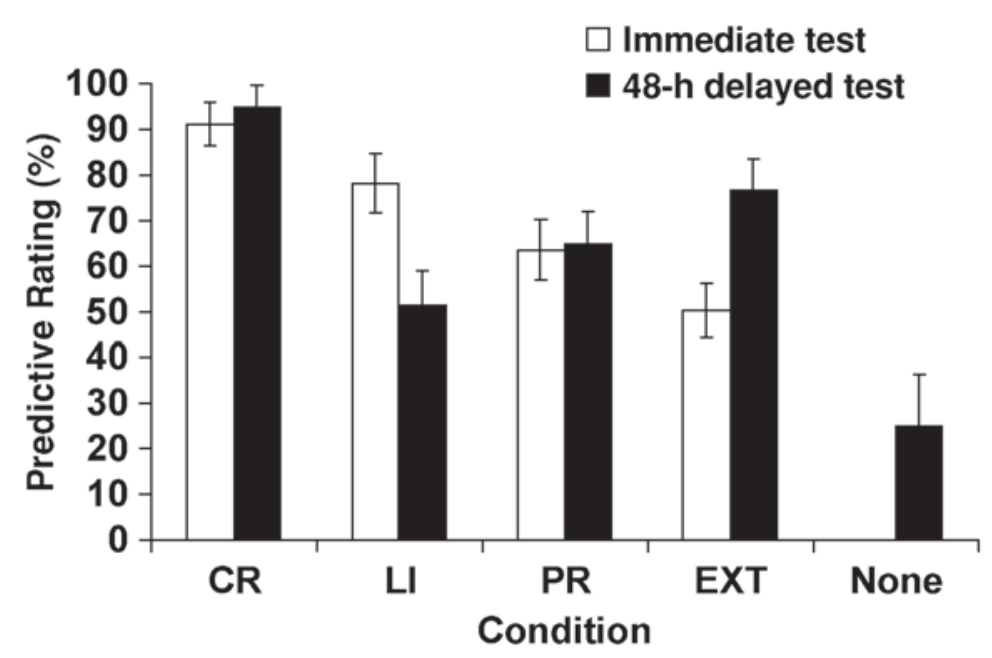

Figure 1. Predictive ratings following three different trial order manipulations of $50 \%$ reinforcement analogous to latent inhibition (LI), partial reinforcement (PR), and extinction (EXT), plus continuous reinforcement (CR) and nonreinforcement (None) treatments. Ratings are plotted as a function of the retention interval interpolated between training and testing.

the EXT-Long group, 1 from the CR-Long group, 2 from the None group, and 1 from the CR-Short group. All the subjects returned after the retention interval; therefore, no subjects were dropped on this basis. The first set of analyses simply compared the two subgroups constituting the CR-Short group with each other on both the immediate test and the 48-h test, the two subgroups constituting the CR-Long group with each other on the 48-h test, and the two subgroups constituting the None group with each other on the 48-h test (see Table 1). None of these comparisons proved significant $($ all $F \mathrm{~s}<1)$. Thus, when there was no ambiguous training, it made no appreciable difference whether training occurred in Phase 1 or in Phase 2. Consequently, the two subgroups were pooled for each of these three groups.

The next set of analyses addressed the six groups that comprised the factorial combination of trial order and re- tention interval. A 2 (retention interval) $\times 3$ (trial order) ANOVA showed an interaction $\left[F(2,73)=7.75, M S_{\mathrm{e}}=\right.$ $604, p<.001]$ but no main effect of either variable $\left(F_{\mathrm{s}}<\right.$ 1). Treatment order effects were assessed using two separate ANOVAs, each restricted to one retention interval, using the error term from the factorial analysis $\left(M S_{\mathrm{e}}=\right.$ 604). A linear trend in trial order for the subjects tested immediately following training was observed $[F(1,73)=$ $6.80, p<.05]$, consistent with a recency effect in the pattern of mean differences (i.e., LI $>$ PR $>$ EXT). In contrast, a linear effect of trial order for the subjects tested only after the 48 -h retention interval $[F(1,73)=8.77$, $p<.01]$ was observed, consistent with a primacy effect in the pattern of mean differences (i.e., EXT $>$ PR $>$ LI). The effect of retention interval at each level of trial order assesses the potential for a recency-to-primacy shift. A

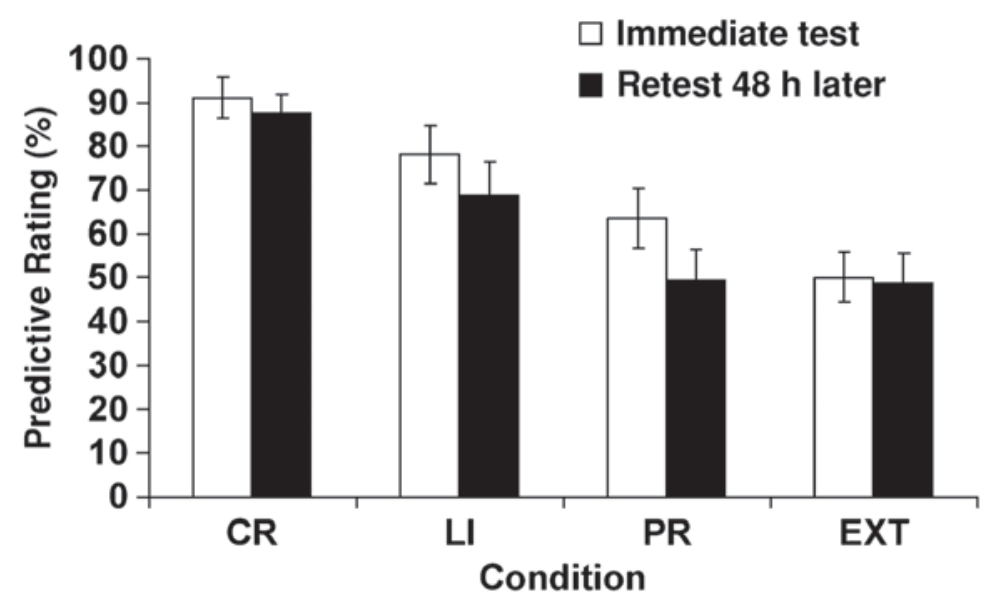

Figure 2. Predictive ratings for subjects who were tested after a short retention interval (7 sec) and again after a long retention interval (48 h). 
recency-to-primacy shift is consistent with lower ratings at the long, relative to the short, retention interval by the subjects who received the LI sequence $[F(1,73)=7.95$, $p<.01$ ], suggestive of enhanced LI. In contrast, the subjects in the EXT condition showed higher ratings after the retention interval $[F(1,73)=7.52, p<.01]$, indicative of spontaneous recovery from EXT. There was no change in ratings for the subjects in the PR condition $(F<1)$, indicating that the uniform distribution of trial types in this condition, which precluded a trial order effect, did not show any effect of the retention interval.

A separate ANOVA comparing groups CR-Long and None (both tested following the 48-h retention interval) demonstrated that acquisition of predictive judgments was specific to the stimulus paired with the outcome $\left[F(1,22)=40.14, M S_{\mathrm{e}}=729, p<.001\right]$. A comparison of CR-Short with CR-Long indicated that little change in ratings occurred with time following continuous reinforcement treatment $(F<1)$. The latter observation suggests that the overall impact of forgetting, which is classically greatest at high response levels (i.e., forgetting functions represent exponential decay), was minimal in this study. A final use of the CR data was to establish the existence of LI, partial reinforcement, or EXT response deficits. Planned comparisons restricted to the four short retention interval groups and using the error from their ANOVA $\left[F(3,51)=8.62, M S_{\mathrm{e}}=474, p<.001\right]$ indicated no significant LI deficit $[F(1,51)=2.20, p>.14]$, a significant partial reinforcement effect $[F(1,51)=9.98, p<.01]$, and a significant EXT effect $[F(1,51)=22.84, p<.001]$. Notably, the absence of a significant LI effect with the short retention interval was not surprising. LI is most evident with many nonreinforced trials and a few reinforced trials. We equated the number of trial types intentionally to obtain weak LI with the short retention interval, so as to increase our sensitivity to any potential enhanced LI effect. Planned comparisons restricted to the four long retention interval groups, excluding the None group, using the error term from their ANOVA $\left[F(3,48)=8.28, M S_{\mathrm{e}}=\right.$ $553, p<.001$ ], indicated the opposite pattern in $F$ values. Following the retention interval, there was an LI deficit $[F(1,48)=23.21, p<.001]$ and a partial reinforcement effect $[F(1,48)=10.68, p<.01]$, but only a marginal EXT effect $[F(1,48)=3.82, p=.056]$. Finally, a 2 (LI vs. CR) $\times 2$ (long vs. short) ANOVA detected an effect of reinforcement probability $\left[F(1,48)=22.30, M S_{\mathrm{e}}=\right.$ $465, p<.001]$, a marginal effect of retention interval $[F(1,48)=3.60, p>.06]$, and an interaction $[F(3,48)=$ $11.27, p<.001]$. This interaction is consistent with more LI at the long retention interval, confirming an enhanced LI effect for the first time outside of a conditioned taste aversion preparation and for the first time in humans.

Although it was not the main focus of the study, a second set of ratings was collected from LI, PR, and EXT subjects in the short condition after they had returned following the 48-h retention interval. A 2 (retention interval) $\times 3$ (trial order) mixed ANOVA was conducted on these scores to assess the validity of the graphical suggestion that these variables did not interact in these subjects.
This analysis indicated main effects of retention interval $[F(1,34)=4.71, p<.05]$ and trial order $[F(2,34)=4.56$, $p<.05]$ but no interaction of the two $[F(2,34)=1.31$, $p>$.28]. Seemingly, the subjects tested a second time gave responses that were similar to their first rating. That is, their ratings were still biased by recency after $48 \mathrm{~h}$, although overall, their ratings were somewhat lower than previously observed.

\section{DISCUSSION}

The experiment demonstrated that responding in a predictive judgment task was biased toward more recent trial types when subjects were asked to give their ratings immediately following the treatment sequence and, further, that predictive ratings shifted to become biased toward early-experienced trial types when the subjects were asked to give their ratings for the first time $48 \mathrm{~h}$ following the treatment sequence. These results replicate Vila and Rosas's (2001) previous demonstration with human subjects of spontaneous recovery from EXT in a medical diagnosis task following a 48-h retention interval, reports involving human subjects in recognition and recall tasks (e.g., Knoedler et al., 1999; Neath, 1993; Postman et al., 1968), and reports with animal subjects given LI treatment in conditioning tasks (e.g., De la Casa \& Lubow, 2000, 2002; Wheeler et al., 2004).

The present results also demonstrate, for the first time, an enhancement of LI following a retention interval (i.e., an enhanced LI effect) in predictive judgment. In contrast, the partial reinforcement deficit was unaffected by retention interval. The total pattern observed was that of a recency-to-primacy shift, which has been observed to occur in human memory in several tasks, including paired associates (Postman et al., 1968), visual recognition memory (Neath, 1993; Wright, Santiago, Sands, Kendrick, \& Cook, 1985), auditory memory (Knoedler et al., 1999; Wright \& Roediger, 2003), and words in a sentence (Knoedler et al., 1999). The experiment also addressed the relative effects of three well-known procedures for reducing responding, relative to continuous reinforcement. The results suggest that under normal testing conditions - usually, soon after training - the LI, partial reinforcement, and EXT effects could each be viewed as partial reinforcement deficits, the magnitude of which is additionally affected by the recency of the nonreinforced trials to testing (see Miller \& Escobar, 2002). However, at least in the present experiment, the relative impact of the EXT and LI manipulations was subject to a reversal, with LI producing the greatest deficit when assessment followed the long retention interval. Lubow and De la Casa (2002) and our own lab (Wheeler et al., 2004) have replicated this crossing over of response functions in experiments with rat subjects. Notably, the superiority of the EXT group and the inferiority of the LI group, both relative to the PR group (which is unique to the present study), on the long retention interval test is strong evidence against models that anticipate memory integration of different phases of training with long retention intervals (e.g., Matute et al., 
2002). Rather, our results support a recency-to-primacy shift.

An interesting ancillary finding of this experiment was that predictive ratings of the subjects in the short condition who had already given their rating immediately following training changed little over the 48-h retention interval. These subjects continued to be biased toward the most recent trial types to which these subjects had been exposed. This finding perhaps elucidates the seeming discrepancy between our present results and those of Matute et al. (2002). A central finding of Matute et al.'s study was that little recency bias was observed if their subjects were asked to make ratings globally - that is, only after they had first viewed all of the trial types. But if their subjects were asked to make predictive ratings following each trial, a strong recency bias was observed. Although we cannot explain why Matute et al. failed to find a recency bias in their global condition, as we did here, the two studies differed in a large number of respects, including the nature of the task, the test questions (Matute et al.'s were causal, whereas ours were predictive), and whether the trials were directly experienced, as in our study, or described, as in Matute et al.'s study. However, they did observe the same tendencies in means that we observed, although they did not approach statistical significance. In addition, it is instructive to consider one similarity in the two sets of results and those of Lopez et al. (1998); in each study, the recency bias was more durable if subjects had made a prior estimate. It would seem that early responding makes the recency effect more likely to be observed and, if observed, more likely to survive a retention interval. This protective effect of early testing has been seen in other preparations, human and nonhuman (see, e.g., Wheeler \& Miller, 2005). It may be that subjects are able to save cognitive effort by simply remembering and repeating their last rating.

The present experiment stands as a demonstration that, after opposing relationships are presented in two sequential phases of observation, people's judgment of each relationship can be biased toward recency or primacy, depending on when they are first asked to provide a judgment. One obvious theoretical implication of this observation is that subjects encode both types of trials but access or weight these memories differently, depending on the conditions of testing. They do not simply forget the order of the trials, since order information dominated behavior at the long retention interval, as well as at the short retention interval. That people can form explicit memories of multiple reinforced and multiple nonreinforced trials, as well as the order in which they occurred, and later access these memories to form an estimate of what is likely to happen next has great intuitive appeal. Indeed, informal debriefings of the subjects in this study indicated that they largely remembered the order and number of event types that they had observed, an observation antithetical to most contemporary associative theories of learning.

In contrast, statistical theories (see, e.g., Allan, 1980; Cheng \& Novick, 1990) anticipate that people will remember the number of different events, but not the event order. Relying on conditional probabilities of the cell counts of a contingency matrix, statistical models cannot predict trial order or retention interval effects, since conditional probabilities are not affected by trial order or time. One possible modification of these models, proposed by Lopez et al. (1998), would be to increasingly weight cell counts used to compute the contingency metric according to their ordinal or interval recency at test, relative to training. However, this modification alone would not predict primacy effects after long retention intervals. To predict the observed occurrence of primacy effects when first-phase stimuli were reinstated or the effectiveness of second-phase cues waned, a conditionalizing strategy, such as that proposed by Cheng and Novick, could be added. This view, quite similar to the encoding specificity hypothesis of Tulving and Thomson (1973), proposes that the cell counts used to compute the contingency metric are made conditional on the cell counts' having occurred in the presence of any salient stimuli that were present at test (presumably, after a long retention interval, conditions are similar to those at the beginning of treatment). A combination of both strategies could predict both recency and primacy effects. Alternative accounts might rely on models of human memory that have ascribed primacy effects to better processing of early-sequence material, perhaps due to better attention (Yates \& Curley, 1986) or more rehearsal (e.g., Atkinson \& Shiffrin, 1968), which could be uncovered by the waning effect of interference from recent trial types.

Formal associative models fare better than statistical models in accounting for ordinal recency effects on behavior (Lopez et al., 1998). But like statistical models, prevailing associative models do not have any variables that change with the retention interval (at least retention intervals spent outside the experimental context). For example, most associative models (e.g., Rescorla \& Wagner, 1972) view conditioned responding as resulting from a CS representation's becoming connected with a representation of the US. The strength of this association between the CS and the US is updated on each trial, and information pertaining to individual trials is destroyed, resulting in a summary statistic that is most strongly influenced by the most recent events. In this way, summary statistics in associative models successfully predict robust recency effects. However, there is nothing in these models, as usually proposed, that operates to cause recency to fade with retention interval. These models could be readily expanded in line with Bouton's (1993) informal proposal to have separate associations between CS and US and between CS and no-US for each phase of training and to have the second (or disconfirming) association under conjunctive control of external and internal contextual stimuli. This view readily predicts recency effects that revert to primacy effects as internal contextual stimuli change over time in ways similar to external (e.g., spatial) contextual cues (see, e.g., Spear, 1973), an assumption supported by considerable data (e.g., Bouton, Nelson, \& Rosas, 1999; see Rosas, Vila, Lugo, \& Lopez, 2001, and Vila \& Rosas, 2001, for evidence of this in human contingency judgment). However, this approach must assume 
that first-learned relationships concerning a specific cue are under less conditional control than are later-learned relationships. Of course, with respect to any modification of contemporary models, more work will be necessary to determine the conditions under which predictive judgments change with retention interval.

\section{REFERENCES}

Allan, L. G. (1980). A note on measurement of contingency between two binary variables in judgment tasks. Bulletin of the Psychonomic Society, 15, 147-149.

Allan, L. G. (1993). Human contingency judgments: Rule based or associative? Psychological Bulletin, 114, 435-448.

AtKinson, R. C., \& Shiffrin, R. M. (1968). Human memory: A proposed system and its control processes. In K. W. Spence \& J. T. Spence (Eds.), The psychology of learning and motivation (Vol. 2, pp. 89195). New York: Academic Press.

Bouton, M. E. (1993). Context, time, and memory retrieval in the interference paradigms of Pavlovian learning. Psychological Bulletin, 114, 80-99.

Bouton, M. E., Nelson, J. B., \& Rosas, J. M. (1999). Stimulus generalization, context change, and forgetting. Psychological Bulletin, 125, 171-186.

BuRdick, C. K., \& JAMES, J. P. (1970). Spontaneous recovery of conditioned suppression of licking by rats. Journal of Comparative \& Physiological Psychology, 72, 467-470.

Cheng, P. W., \& Novick, L. R. (1990). Covariation in natural causal induction. Psychological Review, 99, 365-382.

Collins, D. J., \& Shanks, D. R. (2002). Momentary and integrative response strategies in causal judgment. Memory \& Cognition, 30, $1138-1147$.

Crowder, R. G. (1976). Principles of learning and memory. Hillsdale, NJ: Erlbaum.

De La CASA, L. G., \& Lubow, R. E. (2000). Super-latent inhibition with delayed conditioned taste aversion testing. Animal Learning \& Behavior, 28, 389-399.

De la Casa, L. G., \& Lubow, R. E. (2002). An empirical analysis of the super-latent inhibition effect. Animal Learning \& Behavior, 30, 112-120.

Dennis, M. J., \& AhN, W.-K. (2001). Primacy in causal strength judgments: The effect of initial evidence for generative versus inhibitory relationships. Memory \& Cognition, 29, 152-164.

Dickinson, A., Shanks, D., \& Evenden, J. (1984). Judgment of actoutcome contingency: The role of selective attribution. Quarterly Journal of Experimental Psychology, 36A, 29-50.

Ellson, D. G. (1939). Spontaneous recovery of the galvanic skin response as a function of the recovery interval. Journal of Experimental Psychology, 25, 586-600.

Escobar, M., Arcediano, F., \& Miller, R. R. (2002). Latent inhibition and contextual associations. Journal of Experimental Psychology: Animal Behavior Processes, 28, 123-136.

GLUCK, M., \& Bower, G. H. (1988). From conditioning to category learning: An adaptive network model. Journal of Experimental Psychology: General, 117, 227-247.

Hearst, E. (1988). Fundamentals of learning and conditioning. In R. C. Atkinson, R. J. Herrnstein, G. Lindzey, \& R. D. Luce (Eds.), Stevens' handbook of experimental psychology: Vol. 2. Learning and cognition (2nd ed., pp. 3-109). New York: Wiley.

HinTZMAN, D. L. (1984). MINERVA 2: A simulation model of human memory. Behavior Research Methods, Instruments, \& Computers, 16, 96-101.

Jenkins, H. M., \& Ward, W. C. (1965). Judgment of contingency between response and outcomes. Psychological Monographs, 7, 1-17.

Kerr, J. R., Avons, S. E., \& WARD, G. (1999). The effect of retention interval on serial position curves for item recognition of visual patterns and faces. Journal of Experimental Psychology: Learning, Memory, \& Cognition, 25, 1475-1494.

Knoedler, A. J., Hellwig, K. A., \& Neath, I. (1999). The shift from recency to primacy with increasing delay. Journal of Experimental Psychology: Learning, Memory, \& Cognition, 25, 474-487.

Kraemer, P. J., Randall, C. K., \& Carbary, T. J. (1991). Release from latent inhibition with delayed testing. Animal Learning \& Behavior, 19, 139-145.

Lopez, F. J., Shanks, D. R., Almaraz, J., \& Fernandez, P. (1998). Effects of trial order on contingency judgments: A comparison of associative and probabilistic contrast accounts. Journal of Experimental Psychology: Learning, Memory, \& Cognition, 24, 672-694.

Lubow, R. E., \& De la CaSa, L. G. (2002). Superlatent inhibition and spontaneous recovery: Differential effects of pre- and postconditioning CS-alone presentations after long delays in different contexts. Animal Learning \& Behavior, 30, 376-386.

Lubow, R. E., \& Moore, A. U. (1959). Latent inhibition: The effect of nonreinforced preexposure to the conditioned stimulus. Journal of Comparative \& Physiological Psychology, 52, 415-419.

Matute, H., Vegas, S., \& De Marez, P. N. (2002). Flexible use of recent information in causal and predictive judgments. Journal of Experimental Psychology: Learning, Memory, \& Cognition, 28, $714-$ 725.

Miller, R. R., \& Escobar, M. (2002). Learning: Laws and models of basic conditioning. In C. R. Gallistel (Ed.), Stevens' Handbook of experimental psychology: Vol. 3. Learning, motivation, and emotion (3rd ed., pp. 47-102). New York: Wiley.

Neath, I. (1993). Distinctiveness and serial position effects in recognition. Memory \& Cognition, 21, 689-698.

NeAth, I., \& KNoEdLeR, A. J. (1994). Distinctiveness and serial position effects in recognition and sentence processing. Journal of Memory \& Language, 33, 776-795.

Pavlov, I. P. (1927). Conditioned reflexes: An investigation of the physiological activity of the cerebral cortex (G.V. Anrep, Trans.). London: Oxford University Press.

Postman, L., Stark, K., \& Fraser, J. (1968). Temporal changes in interference. Journal of Verbal Learning \& Verbal Behavior, 7, 672694.

RESCORLA, R. A. (1968). Probability of shock in the presence and absence of CS in fear conditioning. Journal of Comparative \& Physiological Psychology, 66, 1-5.

Rescorla, R. A., \& Wagner, A. R. (1972). A theory of Pavlovian conditioning: Variations in the effectiveness of reinforcement and nonreinforcement. In A. H. Black \& W. F. Prokasy (Eds.), Classical conditioning II: Current research and theory (pp. 64-99). New York: Appleton-Century-Crofts.

Rosas, J. M., Vila, N. J., Lugo, M., \& Lopez, L. (2001). Combined effect of context change and retention interval on interference in causality judgments. Journal of Experimental Psychology: Animal Behavior Processes, 27, 153-164.

ShANKs, D. R., \& DiCKINSON, A. (1987). Associative accounts of causality judgment. In G. H. Bower (Ed.), The psychology of learning and motivation (Vol. 21, pp. 229-261). San Diego: Academic Press.

Shanks, D. R., Holyoak, K. J., \& Medin, D. L. (Eds.) (1996). Causal learning: The psychology of learning and motivation (Vol. 34). New York: Academic Press.

Spear, N. E. (1973). Retrieval of memory in animals. Psychological Review, 80, 163-194.

Tulving, E., \& Thomson, D. M. (1973). Encoding specificity and retrieval processes in episodic memory. Psychological Review, 80 , 359-380.

Van Hamme, L. J., \& Wasserman, E. A. (1994). Cue competition in causality judgments: The role of nonpresentation of compound stimulus elements. Learning \& Motivation, 25, 127-151.

Vila, J., \& Rosas, J. M. (2001). Renewal and spontaneous recovery after extinction in a causal-learning task. Mexican Journal of Behavior Analysis, 27, 79-96.

Wheeler, D. S., \& Miller, R. R. (2005). Primacy effects induced by temporal or physical context shifts can be attenuated by a preshift test trial. Manuscript submitted for publication.

Wheeler, D. S., Stout, S. C., \& Miller, R. R. (2004). Interaction of retention interval with CS-preexposure and extinction treatments: Symmetry with respect to primacy. Learning \& Behavior, 32, 335347. 
Wright, A. A., \& RoEdiger, H. L., III (2003). Interference processes in monkey auditory list memory. Psychonomic Bulletin \& Review, 10, 696-702.

Wright, A. A., Santiago, H. C., Sands, S. F., Kendrick, D. F., \& Cook, R. G. (1985). Memory processing of serial lists by pigeons, monkeys, and people. Science, 229, 287-289.

Yates, J. F., \& Curley, S. P. (1986). Contingency judgment: Primacy effects and attention decrement. Acta Psychologica, 62, 293-302.

Young, M. E. (1995). On the origin of personal causal theories. Psychonomic Bulletin \& Review, 2, 83-104.

\section{NOTE}

1. A caveat demonstrated by De la Casa and Lubow (2000) is that the retention interval must be spent in a context different from that of training for super LI to be observed. Otherwise, recovery from LI is observed (e.g., Kraemer, Randall, \& Carbary, 1991). Extinction of the training context is known to attenuate LI (e.g., Escobar, Arcediano, \& Miller, 2002). The present research avoided confounding the retention interval with context extinction, in that the retention interval was spent outside of the training context.

(Manuscript received August 5, 2004;

revision accepted for publication November 15, 2004.) 